\title{
A complex health services intervention to improve medical care in long-term care homes: study protocol of the controlled coordinated medical care (CoCare) study
}

Boris A. Brühmann ${ }^{1 *}$ D, Christina Reese ${ }^{1}$, Klaus Kaier ${ }^{2}$, Margrit Ott ${ }^{3}$, Christoph Maurer ${ }^{3}$, Simone Kunert ${ }^{4}$, Bruno R. Saurer ${ }^{5}$ and Erik Farin ${ }^{1}$

\begin{abstract}
Background: Deficits in general and specialized on-site medical care are a common problem in nursing homes and can lead to unnecessary, costly and burdensome hospitalizations for residents. Reasons for this are often organizational obstacles (such as lack of infrastructure or communication channels) and unfavorable compensation structures, which impede the implementation of adequate medical care. The purpose of this study is to evaluate a complex intervention aiming to improve the coordination of medical care in long-term care nursing homes in Germany. The project aims to optimize the collaboration of nurses and physicians in order to reduce avoidable hospital admissions and ambulance transportations.
\end{abstract}

Methods/design: In a prospective controlled trial, nursing home residents receiving a complex on-site intervention are compared to residents receiving care/treatment as usual. The study will include a total of around 4000 residents in approximately 80 nursing homes split equally between the intervention group and the control group. Recruitment will take place in all administrative districts of Baden-Wuerttemberg, Germany. The control group focuses on the administrative district of Tuebingen. The intervention includes on-site visits by physicians joined by nursing staff, the formation of teams of physicians, a computerized documentation system (CoCare Cockpit), joint trainings and audits, the introduction of structured treatment paths and after-hours availability of medical care. The project evaluation will be comprised of both a formative process evaluation and a summative evaluation.

Discussion: This study will provide evidence regarding the efficacy of a complex intervention to positively influence the quality of medical care and supply efficiency as well as provide cost-saving effects. Its feasibility will be evaluated in a controlled inter-regional design.

Trial registration: WHO UTN: U1111-1196-6611; DRKS-ID: DRKS00012703 (Date of Registration in DRKS: 2017/08/23).

Keywords: Coordinated medical care, Long-term care homes, Computerized documentation system, Hospital admissions, Complex intervention

\footnotetext{
* Correspondence: boris.bruehmann@uniklinik-freiburg.de

${ }^{1}$ Institute of Medical Biometry and Statistics, Section of Health Care Research

and Rehabilitation Research (SEVERA), Faculty of Medicine and Medical

Center, University of Freiburg, Freiburg, Germany

Full list of author information is available at the end of the article
}

(c) The Author(s). 2019 Open Access This article is distributed under the terms of the Creative Commons Attribution 4.0 International License (http://creativecommons.org/licenses/by/4.0/), which permits unrestricted use, distribution, and reproduction in any medium, provided you give appropriate credit to the original author(s) and the source, provide a link to the Creative Commons license, and indicate if changes were made. The Creative Commons Public Domain Dedication waiver (http://creativecommons.org/publicdomain/zero/1.0/) applies to the data made available in this article, unless otherwise stated. 


\section{Background}

With demographic aging in full force, an increasing number of elderly people are being cared for in nursing homes (NHs). Recent reports have indicated an alarming lack of primary on-site care provided in such facilities $[1-4]$, the result of which can be unnecessary, costly and burdensome hospitalizations for residents [2, 5-10]. Previous studies have assessed that a fair amount of hospitalizations could be avoided by expanding on-site primary care [3-5, 11-13]. However, organizational obstacles such as lack of infrastructure or communication channels and unfavorable compensation structures often impede the implementation of adequate medical care $[2,3,14]$. This situation presents an increasing challenge to German physicians as they struggle to coordinate with one another $[3,13]$ and $\mathrm{NH}$ staff $[3-5,7,13]$, hence establishing the need for a more systematic basis for cooperation. Interventions that might improve teamwork within groups of multidisciplinary $\mathrm{NH}$ care providers include advancing communication, regularly scheduled physicians' $\mathrm{NH}$ visits (that are more appropriately compensated), after-hours availability and reducing administrative workload [10, 14-16]. Some of these have been proven to be effective in pilot projects $[1,2,7]$.

Project CoCare (coordinated medical care) aims to improve the coordination of medical care in long-term care NHs by optimizing the collaboration of nursing staff and physicians in order to reduce the number of avoidable hospital admissions and ambulance transportations, which should improve quality and cost-effectiveness of medical care in long-term care NHs.

Additional or altered services in the project's intervention include: on-site visits by physicians joined by nursing staff, the formation of teams of physicians, a computerized documentation system called CoCare Cockpit (CCC), joint trainings and audits, the introduction of structured treatment paths and after-hours availability of medical care.

The intervention is expected to positively influence quality of care and supply efficiency as well as provide cost-saving effects. The residents of long-term care NHs are surveyed about their health status, the perceived quality of medical care and the collaboration between physicians and nursing staff, perceived care continuity and quality as well as satisfaction with various care services. Nursing staff and physicians are asked to assess their collaboration as well as the continuity and quality of care provided.

The project evaluation is comprised of a formative process evaluation and a summative evaluation, with the latter being a control group design. The combination of process and summative evaluation complies with the recommendations for evaluating complex interventions [17]. In the intervention group, the concept outlined above is implemented and individual medical services administered are reimbursed according to a project-specific compensation plan. The intervention group includes all administrative districts of the federal state of Baden-Wuerttemberg, Germany except the administrative district of Tuebingen. The control group receives care/treatment as usual and includes the administrative district of Tuebingen, Baden Wuerttemberg. Each group will consist of approximately $40 \mathrm{NHs}$ (for a total of 80) and include approximately 2000 long-term care home residents per group.

\section{Research aims}

In this paper, we present the study protocol of project CoCare, developed as a nursing home-based intervention to improve the coordination of medical care in long-term care NHs. Additionally, the study aims a) to optimize the collaboration of nursing staff and physicians in order to b) reduce the number of avoidable hospital admissions and ambulance transportations.

\section{Methods/design \\ Study design and setting}

In a prospective controlled trial, the nursing home-based intervention will be tested by comparing an intervention group to a control group (Fig. 1). NHs for the intervention group will be recruited in all administrative districts of Baden-Wuerttemberg, except the administrative district of Tuebingen. NHs in the administrative district of Tuebingen, which was chosen because of its representativeness, will comprise the control group. Each group will include urban and rural districts to ensure that the results can be generalized to regions with different structural conditions (e.g. availability of medical care, long-term care $\mathrm{NH}$ structure).

\section{Intervention}

The following processes and arrangements are introduced in the intervention groups:

A team of general practitioners (GP) looks after the residents of a $\mathrm{NH}$ and coordinates involvement of specialists. Weekly on-site visits take place at fixed times and are joined by nursing staff. Patients are assigned to their designated GP. However, GPs may treat any patient on behalf of another GP and can be reached by phone after office hours.

There are regular visits of specialists, at least quarterly, coordinated by GPs and accompanied by nursing staff. The residents visited are selected by GPs. In important cases, specialized physicians and GPs will try to coordinate their visits to the same day. Additionally, the project supports positioning suprapubic catheters in the $\mathrm{NH}$, not only by offering training courses for physicians, but also by providing a transportable sonography device for each $\mathrm{NH}$ if necessary. 


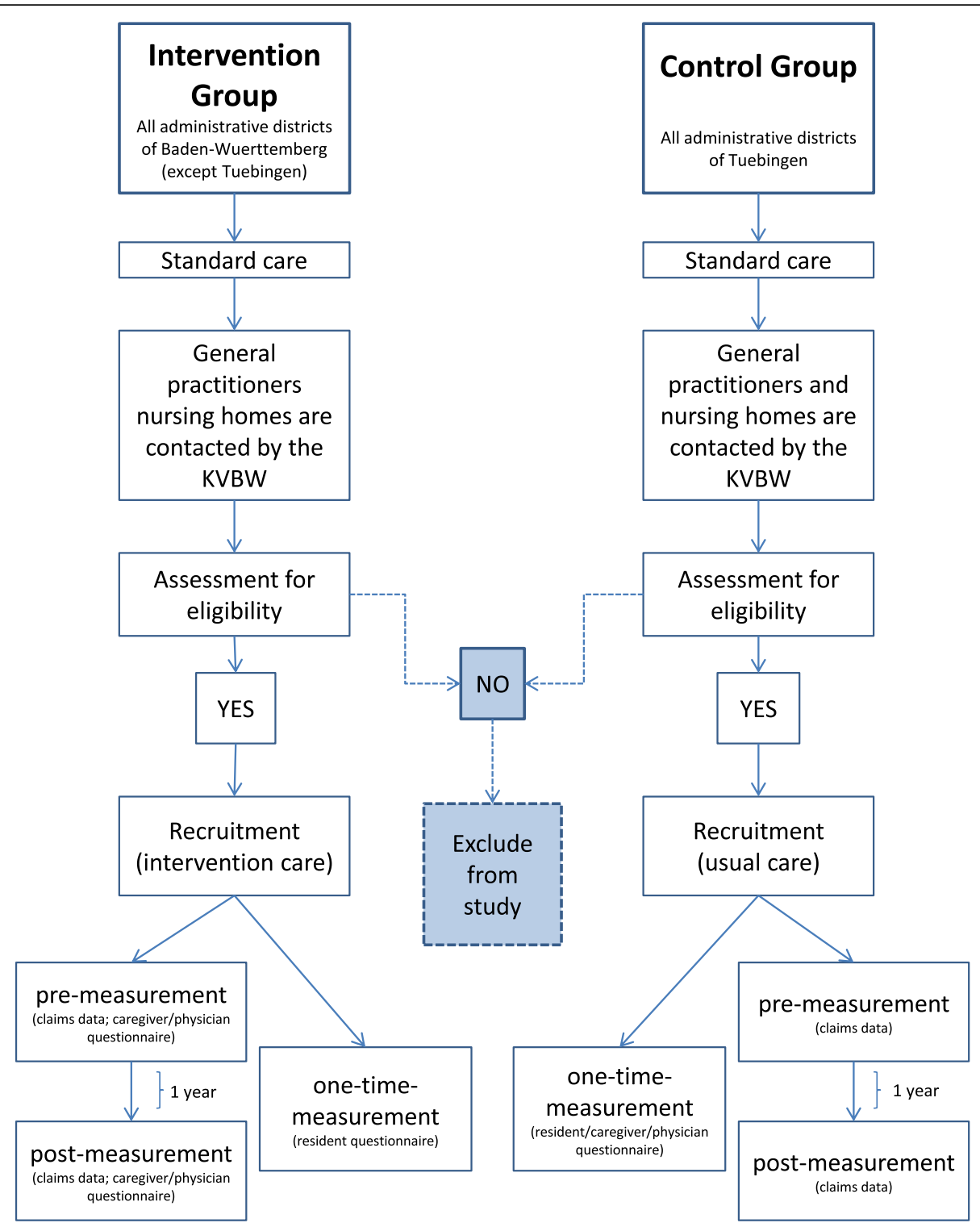

Fig. 1 Study design (File attached); KVBW: Association of Statutory Health Insurance Physicians Baden Wuerttemberg

Standards and structured processes are facilitated between physicians and nursing staff. This includes structured workflows for unplanned cases, e.g. managing a crisis, as well as coordinating a consultation with physicians to prevent hospitalization. For this reason, treatment procedures (e.g., regarding pain) are structured and developed to involve all specialists and GPs.

To expand on usual medical care, the intervention includes coordinated medication management. Medication plans are written by GPs and monitored quarterly. For issues known to lead to frequent hospitalization of patients, structured preventive measures will be established and supported by checklists and action guidelines.
The project aims to improve communication and collaboration between physicians and nursing staff. This will be achieved by appointing study coordinators (CoCare study coordinators) at each participating $\mathrm{NH}$ as designated points of contact for physicians. CoCare coordinators are in charge of tasks such as documentation, preparation and follow up of on-site physician visits, etc.

In the intervention group individual medical services administered are reimbursed according to a project-specific compensation plan. Physicians are reimbursed for trainings and individual services, including coordinative activities, better reachability, or activities preventing hospitalization. Nursing homes receive a flat fee. 


\section{Nursing homes}

\section{Eligibility criteria and recruitment}

NHs that meet the following criteria are eligible to participate as a study site for the intervention group:

- Agree to install a secure internet connection that enables the use of the computerized documentation system CCC

- Collaboration with a team of GPs participating in the study

- Authorization according to Article 72 of Volume XI of the Social Insurance Code (Elftes Buch Sozialgesetzbuch - SGB XI)

The eligibility criteria for $\mathrm{NHs}$ in the control group are only the authorization according to Article 72 of Volume XI of the Social Insurance Code. GPs, who want to participate in the study, have to be willing to build a team with other GPs.

NHs and GPs were contacted and informed about the project by the Association of Statutory Health Insurance Physicians Baden Wuerttemberg (KVBW). NHs which met the criteria were invited to join the study. Based on their location, the NHs were assigned to either intervention or control group.

\section{Training for nursing staff and physicians}

One-day intensive training courses will optimize collaboration between physicians and nursing staff. To ensure structured and coordinated medical care, the courses are attended by both nursing staff and physicians and are based on treatment pathways developed by the Centre for Geriatric Medicine and Gerontology (ZGGF), Freiburg, Germany using recent literature $[18,19]$. Since the project supports the correct changing of a catheter within an instructed time, the ZGGF also offered training courses for physicians in this regard.

Both nursing staff and physicians undergo additional training to work with the newly developed computerized documentation system named CoCare Cockpit (CCC). $\mathrm{CCC}$ is a web-based application that was developed by the nubedian $\mathrm{GmbH}$ for easy documentation and improved information and data management.

\section{Participants \\ Sample size}

The study aims to include about 2000 residents in approximately $40 \mathrm{NHs}$ in both the intervention and control group. In addition, $160 \mathrm{NH}$ residents or relatives of $\mathrm{NH}$ residents and 80 nurses/physicians will participate in focus group interviews.

Using the Power and Sample Size Calculation software "Power and Precision" version 2.0 (Biostat), 253 participants are required per study group ( $80 \%$ power sample and $p=.05$; not considering potential dropouts) [20]. Because of the cluster design, it is necessary to calculate the design effect [21]. For a non-randomized controlled trial with approximately 50 observations in each cluster and intra-cluster correlation of $\rho=0.01$, the design effect is calculated using the following formula:

$\mathrm{DE}=1+0.01 \times(50-1)=1.49$.

Therefore, a total of 377 cases $(1.49 * 253)$ in both the intervention and control group are necessary. To allow for potential dropouts, $n=2000$ participants were included in each group, since there is considerable uncertainty in the estimates. Thus, an unknown rate of missing values will most likely not affect quality of statistical analysis.

\section{Recruitment of participants}

$\mathrm{NH}$ residents, being potential participants, are contacted by their NH staff or their physician. Those who agree to join the study are assigned to either intervention or control group, based on the location of their NH. Exclusion criteria included dementia (for surveys and focus groups) and a residence time less than 3 months (Table 1).

In the intervention group, coordinated medical care as outlined above is implemented. The intervention includes: establishing medical teams; a computerized documentation system named CoCare Cockpit (CCC); joint training courses and audits; joint on-site visits; annual meetings of all participating physicians and $\mathrm{NH}$ coordinators; quarterly meetings between GPs and NH coordinators; interdisciplinary, indication-specific case conferences as needed; standards and structured processes between the physician team and nursing staff; coordinated medication management; structured preventive measures; and extended availability of physicians. At baseline, study eligibility is screened for and informed consent of each participant is obtained in writing by the nursing staff before the recruited resident completes any questionnaire.

The control group participant receives care/treatment as usual based on the established care practices in their $\mathrm{NH}$. At baseline, following the same inclusion/exclusion criteria as the intervention group (Table 1), informed consent is obtained in writing by the nursing staff before the recruited participant completes any questionnaire. Questionnaires will be provided by the nursing staff in

Table 1 Participant eligibility criteria for residents

\begin{tabular}{ll}
\hline Inclusion & Exclusion \\
\hline -Aged $\geq 18$ years old & $\begin{array}{l}\text {-Dementia (only for surveys and focus } \\
\text { groups) }\end{array}$ \\
$\begin{array}{ll}\text {-Resident of a nursing home } \\
\text { in an administrative districts }\end{array}$ & $\begin{array}{l}\text {-Residence time in the long-term } \\
\text { care home below the minimum } \\
\text { in Baden Wuerttemberg }\end{array}$ \\
$\begin{array}{ll}\text {-Member of a statutory health } 3 \text { months } \\
\text { insurance fund }\end{array}$ \\
\hline
\end{tabular}


each individual NH. Basic demographic data is assessed for comparison between participants of control and intervention group.

\section{Study measurements and outcomes Study measurements}

The evaluation is comprised of a formative process evaluation and a summative evaluation, with the latter being a control group design (Table 2).

Process evaluation Process evaluations aim to describe and assess all processes that are relevant to the success of the project. Knowledge gained will be reported back to all involved parties. Main questions of the process evaluation are:

- To what extent are the intervention elements (e.g., documentation of medication in CCC) put into practice?

- What intervention elements were not implemented and for what reasons?

- What contextual conditions were facilitating/ impeding a positive outcome?

- What are the effective mechanisms of the intervention? Which intervention elements are most important?

This evaluation includes focus group interviews, descriptive evaluation of insurance claims data and telephone interviews.

Focus group interviews are used to assess the processes implemented in the intervention. Focus group A, conducted with $\mathrm{NH}$ residents and relatives, discusses aspects of implemented care (e.g., joint visits by physician and nursing staff). Focus group B, including nursing staff and physicians, focuses on administrative aspects such as interdisciplinary, indication-specific case conferences (see also Additional files 1 and 2).

Cost-based claims data from the German system of statutory health insurance is used to assess all elements of the intervention involving residents. This includes aspects such as the completion of on-site visits and medication management.

Non-patient related, organizational aspects of the intervention are assessed by telephone interviews (see also Additional file 3). Interviews with the CoCare study coordinators at each $\mathrm{NH}$ are conducted quarterly. Questions asked during the interviews include: "Did the nursing home appoint a CoCare study coordinator as contact person for GPs?"; "Did the project coordinator of the nursing home organize the on-site visit by the physician?"

The interviews will be used to assess adverse events and will enable the project coordinator to intervene if necessary. Interviews are conducted in both process evaluation and summative evaluation.

Summative evaluation The summative evaluation focuses on the effects of the intervention in terms of its quality and cost indicators compared to the control group.

On an individual level, the following cost indicators will be assessed via claims data: 1. Total cost of hospitalization; 2. Total cost of patient transport; 3 . Total cost of outpatient treatments by GPs; 4 . Total cost of outpatient treatments by medical practitioners; 5 . Total cost of medication and medical supplies; 6 . Assessment of additional cost for measures implemented in the intervention group. Cost-based claims data (indicators $1-5$ ) is provided by the German system of statutory health insurance. Information about additional costs is gathered through intervention-related billing data (indicator 6). All claims data in the intervention and control group was pseudonymized and anonymized, respectively.

Regarding peer assessment, the quality of medical, patient related procedures will be evaluated by the ZGGF via audits. Patient related procedures include correct changing of a catheter within an instructed time. Non-patient related, organizational aspects of the intervention are assessed via telephone interviews by the Section of Health Care Research and Rehabilitation Research, Faculty of Medicine and Medical Center - University of Freiburg (see also Additional file 3). Questions include: "Are on-site visits by specialized physicians accompanied by assigned nursing staff?"

Furthermore, residents will be questioned about additional indicators of quality, including perceived quality of care (with a focus on medical care provided by GPs and cooperation of GPs and nursing staff), overall satisfaction with care in the $\mathrm{NH}$, perceived state of health and overall quality of life. Since no available questionnaire is suitable for this particular intervention, a questionnaire assessing perceived quality of care will be developed. A number of instruments regarding overall satisfaction with care processes are available internationally [22]. However, only few validated and reliable measures are available in German. Hence, a modified version of the commonly used questionnaire "ZUF-A-7" [23] will be used in this study. Perceived state of health and overall quality of life is assessed using the (nationally/internationally) established World Health Organization Quality of Life Questionnaire - WHOQOL-OLD [24] (see also Additional file 4).

Nursing staff are instructed to motivate residents to fill out all questionnaires and assist in case of lack of clarity of questions. However, no additional assistance (such as filling out forms on behalf of a resident or prompting answers) by nursing staff is allowed. In case residents do 


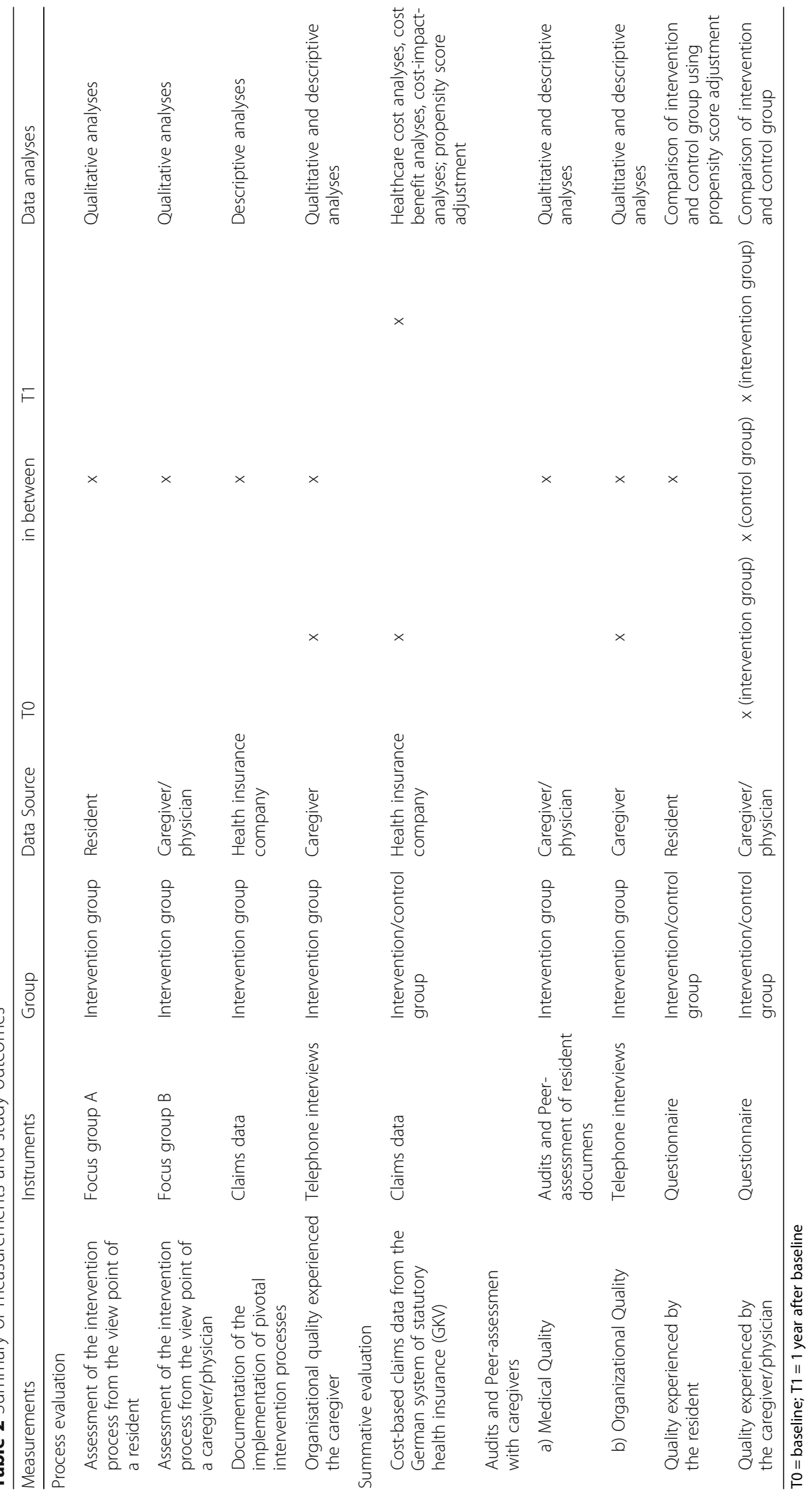


require additional assistance, residents' relatives may be asked to assist filling out questionnaires. Any such assistance is to be documented on the questionnaire.

In addition to patient related processes, the intervention also includes organizational aspects that can only be monitored by nursing staff (e.g., the occurrence of interdisciplinary, indication-specific case conferences). Therefore, nursing staff and physicians will also complete a questionnaire (see also Additional files 5, 6, 7 and 8). Questions are based on work by Körner and Wirtz [25] assessing perceived teamwork of nursing staff and physicians, as well as a questionnaire regarding the working conditions of physicians by Fischbeck and Laubach [26] will be included and address physicians and nursing staff. Data will be collected at two time points: baseline ( $\mathrm{t} 0$ ) and 12 months later ( $\mathrm{t} 1$; Table 2). The control group will be questioned once. All questionnaire data will be assessed anonymously.

\section{Study outcomes}

Primary outcomes of the study are as follows: a) health economic analyses, including total cost of health care (assessment of cost related claims data of the statutory health insurance; pre-post measurement); b) quality of care analyses, including quality of care experienced by residents, physicians and nursing staff (questionnaires for residents, physicians and nursing staff; audits). Data will be included for the period of January 1, 2017 until September 30, 2020.

\section{Hypotheses}

The hypothesis for health economic analyses is that the total cost of health care will be lower in the intervention group compared to the control group. Regarding quality of care, the hypothesis for patient reported outcomes is that perceived quality of care as well as overall satisfaction with received care in the $\mathrm{NH}$ is significantly better in the intervention croup compared to the control group, even after adjusting for relevant confounding variables. The hypotheses for nursing staff/physicians reported outcomes are that a) the perceived quality of medical/nursing care is significantly better in the intervention group compared to the control group; and b) the perceived quality of medical/nursing care is evaluated significantly better after conducting the intervention compared to baseline.

\section{Data analysis}

Data will be collected from claims data, audits, telephone interviews, focus groups, and questionnaires (residents, nursing staff and physicians).

Claims data will be used to conduct economic analyses. It will be evaluated to what extent the claiming of benefits (indicators 1-5) differs between both groups regarding time and certain characteristics of the residents (age, gender, care level/care degree, dementia). Subsequently, cost indicators will be aggregated on a residential level. The resulting sum will equate the overall cost of the medical benefits claimed, including project costs. With a cost-benefit analysis, it will be examined to what extent the total cost differs between intervention and control group. Remaining differences between the two groups will be addressed using propensity score adjustment [27]. Results may also be used for budget-impac$\mathrm{t}$-analyses from a health insurance company's perspective. Lastly, quality of life will be linked to the total cost of medical care with a cost-effectiveness analysis. Thereby, improvements in quality indicators such as 'perceived quality of care,' 'overall satisfaction with care,' 'perceived state of health' and 'quality of life' will be analyzed in relation to the costs of medical resource utilization by calculating incremental cost effectiveness ratios.

Because health care costs are not normally distributed, a generalized linear model (GLM) with a gamma distribution and log link transformation will be used for data analysis [28]. To account for the multi-level-structure of the data, a random intercept will be added on the regional or NH level. Finally, regression estimates will be converted back to costs for interpretation. Incremental cost effectiveness ratios and corresponding confidence intervals will be estimated using seemingly unrelated regressions [29].

For the peer assessment, the basis of valuation for the audits will be based on data in the CCC. For non-patient related organizational aspects of the intervention, data will be collected in telephone interviews. Both analyses will be integrated in the report.

Focus group interviews will be recorded. The contentanalytical evaluation of the audio recordings will be based on an approach by Mayring [30] using the ATLAS.ti software [31]. The sample size was chosen based on experiences with previous multicenter studies.

Data collection by questionnaires will apply to residents as well as nursing staff and physicians. Due to numerous factors, the intervention will probably improve residents' quality of life to a lesser extent than quality of care. For this reason, no clear statistically significant superiority is postulated. However, quality of life will be included in the cost-effectiveness analysis to control for unexpected effects of the intervention. In accordance with previous intervention studies, a non-responder rate of $60 \%$ is assumed $[32,33]$. The statistical analysis strategy is the same used with cost data (GLM; taking into consideration the multi-level-structure as well as propensity score adjustment). It is essential to account for the multi-level-structure, since differences between facilities are to be expected. For nursing staff and physician questionnaires, a non-responder rate of $30 \%$ is assumed. 
Subgroup analyses will control for potential differences between professional/occupational groups.

Data will be analyzed using IBM SPSS Statistics for windows [34], MPlus [35] and Stata [36]. Throughout the study, alpha levels will be fixed at $\alpha=0.05$ for all statistical tests.

\section{Discussion}

Exploring and developing new interventions to improve living conditions of residents of long-term care NHs is crucial. Aside from detrimental effects on individual quality of life, the cost of long-term care $\mathrm{NHs}$ has become an increasing financial burden on society. Since a considerable number of hospitalizations could be avoided, this project will determine if improved coordination of medical care and an optimized collaboration of nursing staff and physicians can reduce the number of hospital admissions and ambulance transportations. To our knowledge, this study is the first to develop a complex intervention to positively and efficiently influence quality and cost of care in $\mathrm{NHs}$ as well as evaluate the intervention's feasibility in a controlled design.

\section{Additional files}

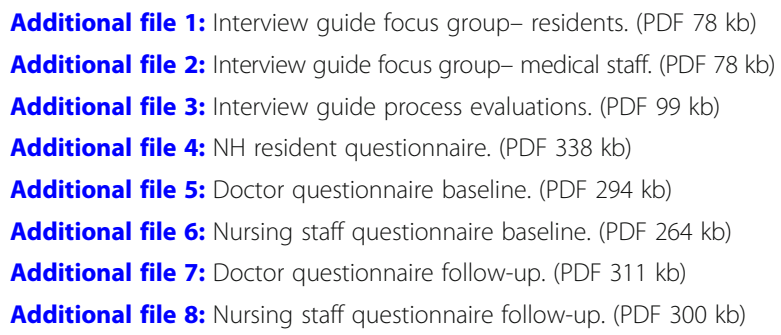

\section{Abbreviations}

CCC: CoCare Cockpit; CoCare: Coordinated medical care; GLM: Generalized linear models; GP: General practitioner; KVBW: Association of Statutory Health Insurance Physicians Baden Wuerttemberg; NH: Nursing home; ZGGF: Centre for Geriatric Medicine and Gerontology

\section{Acknowledgements}

We thank Frederike Bjerregaard, Caroline Broichhagen, Ralph Möller, Anna Wellnitz, Gerlinde Fischer, Sebastian Voigt-Radloff for their contribution to the planning of the clinical part of the study and literature research. We would also like to thank Vanessa Kaiser and Philip Hehn for their help with language revision and Rieka von der Warth and Jonas Schäfer for proofreading. The article processing charge was funded by the German Research Foundation (DFG) and the University of Freiburg in the funding programme Open Access Publishing.

\section{Funding}

This research was funded by the Innovation Committee of the Federal Joint Committee (G-BA) supported by the Innovation Fund. Proposal-ID: NVF1_2016-080.

The funding body had no role in the collection, analysis, and interpretation of study data, nor did they play a role in the writing of the manuscript or the submission of the manuscript for publication.

\section{Availability of data and materials}

Following pleas for full disclosure, all mentioned research materials are made available in Additional file 1, 2, 3, 4, 5, 6, 7 and 8 .

\section{Author's contributions}

$\mathrm{BB}$ is the lead author and wrote the first draft. The study design was done by EF, KK, MO. EF and SK participated in project coordination and project management (e.g., recruitment, data protection, ethical considerations). BB, KK and CR were involved in the preparation of data collection and data analysis. $\mathrm{MO}, \mathrm{CM}$ and $\mathrm{BS}$ were engaged in the development of the computerized documentation system called CoCare Cockpit. All authors provided feedback on the manuscript and read and approved the final version of the manuscript.

Ethics approval and consent to participate Informed consent of each participant (resident/relative/caregiver/physician) is obtained in writing by the nursing staff before the recruited person completes any questionnaire. Ethics Approval of this study was granted by the ethics committee at the Chamber of Physicians of the State of BadenWürttemberg (Reference number: B-F-2017-127; 14.11.2017) as well as by the ethics committee at the University of Freiburg Medical Centre (Reference number: 333/17; 03.08.2017).

\section{Consent for publication}

'Not applicable'

\section{Competing interests}

The authors declare that they have no competing interest.

\section{Publisher's Note}

Springer Nature remains neutral with regard to jurisdictional claims in published maps and institutional affiliations.

\section{Author details}

${ }^{1}$ Institute of Medical Biometry and Statistics, Section of Health Care Research and Rehabilitation Research (SEVERA), Faculty of Medicine and Medical Center, University of Freiburg, Freiburg, Germany. ${ }^{2}$ Institute of Medical Biometry and Statistics, Division Methods in Clinical Epidemiology, Faculty of Medicine and Medical Center, University of Freiburg, Freiburg, Germany. ${ }^{3}$ Centre for Geriatric Medicine and Gerontology (ZGGF), Faculty of Medicine and Medical Center, University of Freiburg, Freiburg, Germany. ${ }^{4}$ Association of Statutory Health Insurance Physicians Baden Wuerttemberg (KVBW), Stuttgart, Germany. ${ }^{5}$ nubedian $\mathrm{GmbH}$, Karlsruhe, Germany.

Received: 6 February 2019 Accepted: 9 May 2019

Published online: 24 May 2019

\section{References}

1. Hallauer J, Bienstein C, Lehr U, Rönsch H. SÄVIP-Studie zur ärztlichen Versorgung in Pflegeheimen. Hannover: Vincentz Network Marketing Service; 2005.

2. Rothgang $H$, Borchert L, Müller R, Unger R. GEK-Pflegereport 2008. Schwerpunktthema: Medizinische Versorgung in Pflegeheimen. GEK Ed Schriftenreihe zur Gesundheitsanalyse. 2008;66.

3. Balzer K, Butz S, Bentzel J, Boulkhemair D, Lühmann D. Beschreibung und Bewertung der fachärztlichen Versorgung von Pflegeheimbewohnern in Deutschland. Schriftenreihe Health Technol Assess. 2013;125:348.

4. Sachverständigenrat zur Begutachtung der Entwicklung im Gesundheitswesen. Koordination und Integration - Gesundheitsversorgung in einer Gesellschaft des längeren Lebens. Baden-Baden: Nomos; 2009. https://www.svr-gesundheit.de/fileadmin/user_upload/Gutachten/2009/ Kurzfassung-2009.pdf. Accessed 9 Apr 2019.

5. Lisk R, Yeong K, Nasim A, Baxter M, Mandal B, Nari R, Dhakam Z. Geriatrician input into nursing homes reduces emergency hospital admissions. Arch Gerontol Geriatr. 2012;55(2):331-7.

6. Sundmacher $L$, Kopetsch $T$. The impact of office-based care on hospitalizations for ambulatory care sensitive conditions. Eur J Health Econ. 2015:16(4):365-75

7. Sachverständigenrat zur Begutachtung der Entwicklung im Gesundheitswesen. Wettbewerb an der Schnittstelle zwischen ambulanter und stationärer Gesundheitsversorgung. Baden-Baden: Nomos; 2012. 
https://www.svr-gesundheit.de/fileadmin/user_upload/Gutachten/2012/ GA2012_Langfassung.pdf. Accessed 9 Apr 2019.

8. Walsh KA, Bruza JM. Hospitalization of the elderly. Ann Long Term Care Clin Care Aging. 2007;15(11):18-25.

9. Hibbeler B. Vereinbarung zu Kooperationsverträgen: Mehr Geld für Arztbesuche im Heim. Dtsch Ärztebl. 2014;110(19):386

10. Kada O, Janig H, Likar R, Pinter G. Versorgung optimieren, vermeidbare Krankenhaustransporte reduzieren. In: Pinter G, Likar R, Schippinger W, Janig H, Kada O, Cernic K, editors. Geriatrische Notfallversorgung. Vienna: Springer Vienna; 2013. p. 227-52.

11. Sundmacher L, Fischbach D, Schuettig W, Naumann C, Augustin U, Faisst C. Which hospitalisations are ambulatory care-sensitive, to what degree, and how could the rates be reduced? Results of a group consensus study in Germany. Health Policy. 2015;119(11):1415-23.

12. Saliba D, Kington R, Buchanan J, Bell R, Wang M, Lee M, Herbst M, Lee $D$, Sur $D$, Rubenstein $L$. Appropriateness of the decision to transfer nursing facility residents to the hospital. J Am Geriatr Soc. 2000;48(2):154-63.

13. Kada O, Brunner E, Likar R, Pinter G, Leutgeb I, Francisci N, Pfeiffer B, Janigb H. Vom Pflegeheim ins Krankenhaus und wieder zurück ... Eine multimethodale Analyse von Krankenhaustransporten aus Alten- und Pflegeheimen. Z Für Evidenz Fortbild Qual Im Gesundheitswesen. 2011; 105(10):714-22.

14. Meyer-Kühling I, Frankenberg C, Schröder J. Erwartungshaltungen, Kommunikation und Kooperation von Pflegenden und Ärzten in der stationären Altenpflege. HeilberufeScience. 2015;6(3):70-5.

15. Karsch-Völk M, Lüssenheide J, Linde K, Schmid E, Schneider A. Was sind die Voraussetzungen für eine erfolgreiche Zusammenarbeit zwischen Pflegeeinrichtung und Ärzten? - Ergebnisse einer Mixed Methods Querschnittserhebung in bayerischen Pflegeeinrichtungen. Gesundheitswesen. 2016;78(11):742-8.

16. Karsch-Völk M, Lüssenheide J, Linde K, Schmid E, Schneider A. Entwicklung eines Kriterienkatalogs für eine gelungene ärztliche Versorgung in Pflegeeinrichtungen. Z Für Evidenz Fortbild Qual Im Gesundheitswesen. 2015;109(8):570-7.

17. Moore GF, Audrey S, Barker M, Bond L, Bonell C, Hardeman W, Moore L, O'Cathain A, Tinati T, Wight D, Baird J. Process evaluation of complex interventions: Medical Research Council guidance. BMJ. 2015;350:1-7.

18. Rotter T, Kinsman L, James EL, Machotta A, Gothe H, Willis J, Snow P, Kugler J. Clinical pathways: effects on professional practice, patient outcomes, length of stay and hospital costs. Cochrane Database Syst Rev. 2010;(3):CD006632.

19. National Institute for Health and Care Excellence. Managing medicines in care homes. https:/www.nice.org.uk/guidance/sc1/resources/managingmedicines-in-care-homes-pdf-61677133765. Accessed 9 Apr 2019.

20. Biostat. Power and Precision. https://www.power-analysis.com. Accessed 9 Apr 2019

21. Kerry SM, Bland JM. Statistics notes: sample size in cluster randomisation. Bmj. 1998;316(7130):549.

22. Jeon Y, Fethney J, Ludford I. Measuring client satisfaction in residential aged care settings: a narrative review of instruments. Internet J Healthc Adm. 2012;8(1):1531-2933

23. Kriz D, Schmidt J, Nübling R. Zufriedenheit von Angehörigen mit der Versorgung in stationären Altenpflegeeinrichtungen. Entwicklung des Screening-Fragebogens ZUF-A-7. Pflege. 2006;19(2):88-96.

24. Power M, Quinn K, Schmidt S. Development of the WHOQOL-old module. Qual Life Res. 2005;14(10):2197-214.

25. Körner M, Wirtz MA. Development and psychometric properties of a scale for measuring internal participation from a patient and health care professional perspective. BMC Health Serv Res. 2013;13:374.

26. Fischbeck S, Laubach W. Arbeitssituation und Mitarbeiterzufriedenheit in einem Universitätsklinikum: Entwicklung von Messinstrumenten für ärztliches und pflegerisches Personal. Psychother Psychosom Med Psychol. 2005;55(06):305-14.

27. Vansteelandt S, Daniel RM. On regression adjustment for the propensity score. Stat Med. 2014;33(23):4053-72.

28. Mullahy J. Econometric modeling of health care costs and expenditures: a survey of analytical issues and related policy considerations. Med Care. 2009;47(7 Suppl 1):S104-8.

29. Willan AR, Briggs AH. Statistical analysis of cost-effectiveness data. Chichester; Hoboken: Wiley; 2006.

30. Mayring P. Qualitative Inhaltsanalyse. 8th ed. Weinheim: Beltz; 2003.
31. Scientific software development $\mathrm{GmbH}$. Atlas. Ti (version 5.2 for windows). https://atlasti.com. Accessed 9 Apr 2019.

32. Budnick A, Jordan L-M, Könner F, Hannemann B, Wulff I, Kalinowski S, Kreutz R, Dräger D. Welche Ausfallursachen liegen bei Pflegeheimbewohner (inne) $\mathrm{n}$ in einer Interventionsstudie vor? Eine Analyse der Unit-Nonresponder in zwölf deutschen Pflegeheimen. Pflege. 2015;28(1):33-45.

33. Oswald WD, Ackermann A, Gunzelmann T. Effekte eines multimodalen Aktivierungsprogrammes (SimA-P) für Bewohner von Einrichtungen der stationären Altenhilfe. Z Für Gerontopsychologie Psychiatr. 2006;19(2):89-101.

34. IBM SPSS Statistics 25 Documentation. http:IIwww.ibm.com/support/ docview.wss?uid=swg27049428. Accessed 9 Apr 2019.

35. Mplus. https://www.statmodel.com. Accessed 9 Apr 2019.

36. Stata: software for Statistics and data science. https://www.stata.com. Accessed 9 Apr 2019.

\section{Ready to submit your research? Choose BMC and benefit from:}

- fast, convenient online submission

- thorough peer review by experienced researchers in your field

- rapid publication on acceptance

- support for research data, including large and complex data types

- gold Open Access which fosters wider collaboration and increased citations

- maximum visibility for your research: over $100 \mathrm{M}$ website views per year

At BMC, research is always in progress.

Learn more biomedcentral.com/submissions 